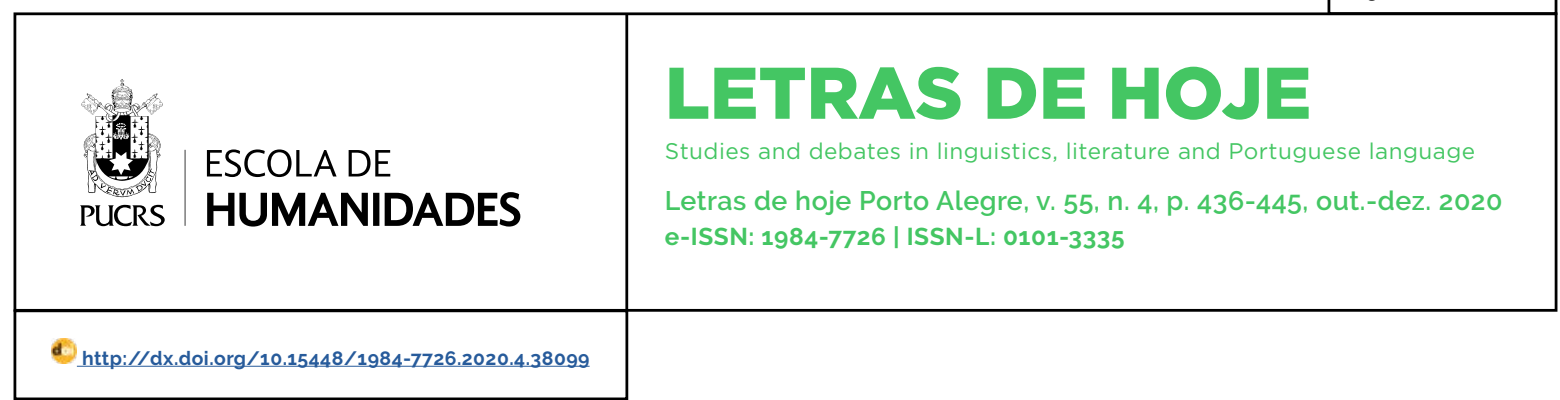

PORTUGUÊS COMO LÍNGUA ADICIONAL: LINGUISTICA E TRADUÇÃO

\title{
Aquisição do artigo definido por aprendizes chineses de PLA
}

\author{
Acquisition of the definite article by Chinese learners of PLA \\ Adquisición del artículo definido por aprendices chinos de PLA
}

\author{
Jing Zhang ${ }^{1}$ \\ orcid.org/0000-0003-4801-6354
}

jingz@um.edu.mo

Recebido em: 5/8/2020

Aprovado em: 11/9/2020

Publicado em: 09/02/2021

\section{(c) (1)}

Artigo está licenciado sob forma de uma licença Creative Commons Atribuição 4.0 Internacional.
RESUMO: O presente estudo visa observar como os aprendizes chineses cuja língua materna não possui o sistema do artigo adquirem o artigo definido (AD) em português como língua adicional (PLA), tentando verificar a omissão e a generalização excessiva deste artigo na sua interlíngua. Além disso, tem também como objetivo determinar se o uso do AD no contexto genérico e nos contextos não genéricos classificados segundo o modelo adaptado do de Liu e Gleason (2002), apresenta uma diferença no nivel de dificuldade para os aprendizes chineses. Neste contexto, foram realizadas entrevistas individuais junto de alunos universitários chineses de português de nível intermédio. Os dados obtidos com base nas análises quantitativas evidenciam a omissão não muito marcada do AD e a generalização excessiva do AD em construções não-padrão da interlingua dos aprendizes chineses onde o $A D$ em português não deve ser usado. Além disso, certos contextos linguísticos não genéricos do AD são mais fáceis do que outros, o que suporta a afirmação de Liu e Gleason (2002). O estudo contribui para mostrar as variações ocorridas no processo da aquisição do AD português por aprendizes chineses de nivel de proficiência intermédio, que devem dedicar esta aquisição do AD ao longo de todo o processo.

Palavras-chave: Artigo Definido. Contextos Genérico e Não Genéricos. PLA. Aprendizes Chineses.

ABSTRACT: The present study aims to observe how Chinese learners whose mother tongue does not have the article system acquire the definite article (AD) in Portuguese as an additional language (PLA), trying to verify the omission and excessive generalization of this article in their interlanguage. In addition, it also aims to determine whether the use of $A D$ in the generic context and non-generic contexts classified according to the model adapted from that of Liu and Gleason (2002), presents a difference in the level of difficulty for Chinese learners. In this context, individual interviews were conducted with Chinese university students of Portuguese at an intermediate level. The data obtained based on quantitative analyzes show not very marked omission of $A D$ and excessive generalization of $A D$ in non-standard constructions of Chinese learners' interlanguage where $A D$ in Portuguese should not be used. In addition, certain non-generic linguistic contexts in $A D$ are easier than others, which supports the statement by Liu and Gleason (2002). The study contributes to show the variations that occurred in the process of acquisition of Portuguese AD by Chinese learners of intermediate proficiency level, who should dedicate this acquisition of AD throughout the whole process. Keywords: Definite Article. Generic and Non-Generic Contexts. PLA. Chinese Learners.

RESUMEN: El presente estudio tiene como objetivo observar cómo los estudiantes chinos, cuya lengua materna no tiene el sistema de articulos, adquieren el artículo definido (AD) en portugués como lengua adicional (PLA), tratando de verificar la omisión y generalización excesiva de este artículo en su interlengua. Además, también tiene como objetivo determinar si existen diversos grados de dificultad si el uso de AD se verifica en el contexto genérico o en contextos no genéricos, de acuerdo con un modelo adaptado del de Liu y Gleason (2002). Para ello se realizaron entrevistas individuales a estudiantes universitarios chinos de portugués intermedio. Los datos obtenidos en base a los análisis cuantitati- 
vos muestran la omisión no muy marcada de AD y la generalización excesiva de $A D$ en construcciones no estándar de la interlengua de los estudiantes chinos, en las cuales no debería usarse el $A D$ en portugués. Además, ciertos contextos lingüísticos no genéricos en la EA son más fáciles que otros, lo que respalda la afirmación de Liu y Gleason (2002). El estudio ayuda a mostrar las variaciones que se verifican en el proceso de adquisición de AD portugués por parte de aprendices chinos de nivel intermedio, quienes deberían dedicar esta adquisición de AD durante todo el proceso.

Palabras clave: Artículo definido. Contextos genéricos y no genéricos. PLA. Aprendices chinos.

\section{Introdução}

Os aprendizes chineses encaram muitas dificuldades na sua aquisição do sistema do artigo em línguas adicionais ( $L A)^{2}$, cometendo erros de vários tipos. Um dos fatores relacionados com o uso desviado do artigo é a transferência negativa de lingua materna, uma vez que esse sistema se encontra ausente na língua chinesa. Além disso, fatores ligados a LA também contribuem para explicar o uso problemático do artigo, exemplificando-se a generalização excessiva de regras gramaticais. Esses fenômenos foram revelados por muitos estudos conduzidos em redor dos aprendizes chineses a adquirir o sistema do artigo em inglês (THOMAS, 1989; ROBERTSON, 2000; LU, 2001; LIU e GLEASON, 2002; LARDIERE, 2004; YANG e HE, 2016). Além disso, para aprendizes cuja língua materna não possui o sistema do artigo, o mapeamento entre os traços disponiveis na língua materna com novas morfologias, por exemplo, o artigo definido (AD), numa LA continua desafiador, mesmo em niveis relativamente altos de proficiência (CHO e SLABAKOVA, 2014; LARDIERE, 2016; SNAPE, 2018).

Este estudo examina a variação na aquisição do AD na interlingua de aprendizes chineses universitários com o nivel intermédio de proficiência de português, especialmente nos diferentes contextos linguísticos. Os usos do AD enquadram-se em duas categorias principais: genérica e não genérica.

O uso genérico refere-se a casos em que o AD é usado para significar uma espécie, ou um grupo. To- dos os outros usos são considerados não genéricos. No estudo atual, os contextos não genéricos são classificados de acordo com um modelo adaptado com base no modelo de Liu e Gleason (2002), que apresentou a classificação dos usos não genéricos do AD inglês em quatro categorias, sendo cultural, situacional, estrutural e textual. Os seus resultados indicaram a hierarquia de dificuldade na aquisição dos quatro usos não genéricos, o mais difícil dos quais é cultural e o mais fácil é situacional.

O presente texto começa por se referir a estudos anteriores sobre a aquisição do AD, ilustrando a classificação adotada, neste estudo, dos contextos em que é pedido o AD em português. A metodologia e os resultados das análises quantitativas encontram-se apresentados no seguinte. O texto finaliza-se com a parte conclusiva.

\section{Artigo definido}

Dentre os estudos realizados na área da aquisição, há evidência de que as propriedades de língua materna influenciam a aquisição do AD. Os aprendizes de língua materna que não possui o artigo têm que estabelecer uma especificação nova para uma categoria funcional na sua aquisição de LA. É constatado que a transferência negativa causa a omissão do artigo e os aprendizes que têm esta categoria gramatical na sua lingua materna desempenham de melhor forma na aquisição do artigo do que os que não têm (MASTER, 1987; YOUNG, 1996; PARODI et al., 1997; MURPHY, 1997; ROBERTSON, 2000; IONIN et al., 2008). Por isso, o primeiro objetivo do presente estudo é examinar se a omissão do AD ocorre a aprendizes chineses de PLA

Por outro lado, é verificada a generalização excessiva do AD. Huebner (1983; 1985) mostrou como um falante nativo do Laos generalizou o uso do AD em diferentes fases do desenvolvimento da interlingua. Os fatores de LA, neste caso, influenciam o processo da aquisição, tendo sido usado o artigo onde esse não era pedido. Este fenômeno da generalização excessiva de regras gramaticais de LA foi notado por Master 
(1987), Chaudron e Parker (1990) e Young (1996), o que também constitui um dos objetivos do presente estudo.

Existe ainda um número de estudos a aprovar que o AD é usado com mais exatidão do que o artigo indefinido (Al). A este fenômeno Mayo (2009) denomina de "direccionalidade" na aquisição do artigo dado que reflete o padrão de desenvolvimento da aquisição do artigo. Os estudos de Robertson (2000), Lardiere (2004) e White (2003) suportam este achado, verificando que os aprendizes de língua materna sem o sistema de artigo são significativamente mais corretos no uso do AD do que no uso do Al. Portanto, é importante observar se o uso do AD em português por aprendizes chineses é mais correto do que o uso do Al.

Outra questão que se coloca diz respeito ao desempenho dos aprendizes no uso do AD: será que os aprendizes chineses são corretos em todos os contextos do uso do AD? A questão é abordada em duas categorias: genérica e não genérica.

Em primeiro lugar, o AD pode ser usado para exprimir a totalidade específica de um gênero, de uma categoria, de um grupo, de uma substância. Trata-se do seu emprego genérico (CUNHA e CINTRA, 2002, p. 218). Quanto aos usos não genéricos, tenta-se estabelecer um modelo próprio que se adeque melhor ao presente estudo.

Liu e Gleason (2002) combinaram os oito usos não genéricos do $A D$ inglês da taxonomia de Hawkins (1978), classificando-os em quatro tipos: o uso textual com um nome anteriormente mencionado ou com um nome ligado a outro nome anteriormente mencionado. Este grupo inclui o uso anafórico e o uso anafórico associativo de Hawkins; o uso estrutural que inclui o uso com um nome de primeira menção que tem um modificador explicativo na forma de uma oração, locução prepositiva, ou nome; o uso situacional em que o referente de um nome de primeira menção pode ser sentido direta ou indiretamente pelos locutores envolvidos ou o referente é conhecido pelos membros da comunidade local. Este tipo inclui o uso de situação visível, o uso de situação imediata e o uso de situação maior dependente de conhecimentos especíicos; o uso cultural com um nome que se refere a um referente único e muito conhecido na comunidade discursiva. Por isso, este uso é determinado pela prática convencional.

No seu estudo foi examinado o uso do AD junto de um grupo de informantes oriundos da China, Coreia e Japão e de outro grupo de informantes das línguas indo-europeias, divididos em três niveis (elementar, intermédio e avançado) e a frequentar programas intensivos de inglês em diversas universidades nos EUA. Segundo os dados, existem diferenças significativas entre o grupo de falantes cujas línguas maternas não têm o artigo e o outro com línguas maternas que têm o artigo na omissão do $A D$ em diferentes usos do AD. Além disso, a ordem da aquisição sugere que certos usos são mais fáceis para os aprendizes. O uso situacional do AD é anterior aos usos estrutural e textual, e a aquisição dos usos estrutural e textual é anterior ao uso cultural que é o mais difícil.

Chen (2004) identificou a base cognitiva de identificabilidade: co-presença física e linguística diretamente; compartilhamento de conhecimento. O AD, derivado diacronicamente de um pronome demonstrativo, tem usos divididos em quatro categorias - situacional, anafórico, compartilha do conhecimento especifico ou geral, e associativo. O AD difere do demonstrativo em dois aspetos principais: primeiro, enquanto o $A D$ tem usos adjetivais, o demonstrativo tem tipicamente usos adjetivais, pronominais e adverbiais. Segundo, a função primária do demonstrativo é a de deítico, e o AD é neutro deiticamente.

Tendo como objetivo principal investigar o processo de aquisição do AD em português como segunda língua por aprendizes coreanos, Kim (2005) levou a cabo um estudo recorrendo a entrevistas, narrativa com base em gravuras e descrição oral de uma figura. Categorizou, no seu estudo, as funções do AD em vários contextos: uso de primeira menção, uso de segunda menção e uso genérico. Segundo os seus resultados, o $A D$ é usado com maior adequação com as seguintes categorias: referente óbvio, expressões de tempo, antes de topónimos e antes de nomes de instituições, obras construidas e siglas. Nesses 
casos também está inferido que o uso do AD está relacionado com a contração com preposições. Além disso, encontraram-se outras caracteristicas do processo da aquisição: o uso do pronome demonstrativo (esse/essa) para marcar a segunda menção; a autocorreção para usar o AD; o uso diante de "casa" em relação às preposições (em, a, de, para); o uso opcional com "todo(s)/toda(s)"; o uso em relação ao tempo verbal; a tendência do uso do AD na contração com preposições.

Para se explicitar como funcionam as operações de determinação em português, Mateus et al. (2003) descreveram que as operações de definitização fazem corresponder a uma dada expressão linguística um único objeto identificado para o locutor, e pressuposto por este como identificável pelo(s) interlocutor(es).

Com base nos estudos de Hawkins (1978), Liu e Gleason (2002), Cunha e Cintra (2002), Mateus et al. (2003), Chen (2004), Kim (2005), são definidos os contextos do uso do AD em português para o nosso estudo. Aqui, o AD é aplicado em contextos em que uma entidade pode ser considerada determinada pelo locutor e interlocutor em virtude de uma variedade de fontes de identificação:

1. A determinação da entidade é diretamente evocada a partir da sua presença física no contexto de discurso (Uso situacional):

$$
\text { E1 Passa-me o pão? }
$$

2. A determinação da entidade é diretamente evocada a partir da parte anterior do enunciado ${ }^{3}$ (Uso anafórico).

E2 Há um cão e um gato no meu jardim. O cão gosta de correr atrás do gato.

3. A determinação da entidade é estabelecida na base do conhecimento especifico compartilhado entre o falante e o ouvinte sobre os ambientes físicos e linguísticos. Também se incluem "o sol", "a lua", com referentes únicos e "a Universidade de Macau", "o Banco da China" e outros substantivos próprios, conhecimento geral partilhado pelo falante e ouvinte (Conhecimento compartilhado). E3 Onde está o cão?

E4 A Universidade de Macau localiza-se na Itha da Taipa.

4. A determinação de um referente é indicada a partir de outras entidades ou atividades no discurso através do raciocínio lógico na base do conhecimento geral da inter-relação entre as entidades ou atividades envolvidas (Referência por associação).

E5 A Maria entrou no centro comercial às 9 horas. As lojas estavam ainda fechadas.

5. A referência definida é derivada a partir da sua associação com a informação que está contida na própria expressão nominal (Informação contida na própria expressão nominal).

E6 Conheces o homem com quem ela foi jantar ontem à noite?

6. A referência definida reveste-se de um sentido genérico (Genérico).

E7 O cão é um fiel amigo do homem.

É posto um ponto isolado em que a colocação de $A D$ parece um uso automático e fixo. Assim temos:

7. A aplicação fixa de uma expressão nominal (Usos fixos)

E8 O João sentiu-se mal e foi ao médico imediatamente.

No nosso estudo, as análises realizadas sobre o uso do AD nos sete contextos acima descritos vão mostrar quais são aqueles definidos em que o AD ocorre com mais frequência; se certos usos não genéricos do AD são mais fáceis do que outros, por exemplo, o uso situacional é mais fácil do que os usos estrutural e textual.

Em português, a determinação é marcada pelos morfemas tipicamente gramaticais e funcionais, tal como o AD. Por outro lado, os principais determinantes definidos em chinês são os demonstrativos zhe, na, e as suas formas plurais

\footnotetext{
3 Trata-se do uso anafórico. Segundo Mateus et al. (2003, p. 801 e 802), a anáfora é considerada uma figura de estilo que consiste na repetição de uma palavra ou de um grupo de palavras no início de enunciados sucessivos. E na Linguistica moderna, o conceito de anáfora não é uniforme, tendendo a ser visto como o processo que consiste em utilizar uma forma linguística ou um vazio para remeter para algo que foi dito anteriormente (o antecedente). O que nos interessa aqui é a anáfora nominal.
} 
zhexie, naxie. Além de preservarem a sua força deitica, desenvolvem funções do AD em português, marcando referentes cuja determinação é estabelecida através da partilha de conhecimento, e do uso anafórico e associativo.

No entanto, são pouco usuais em estruturas consideradas prototípicas do AD, sobretudo no que se refere à determinação respeitante à partilha do conhecimento específico ou geral, ou à referência indireta por associação (ZHANG, 2014. p. 81). Além disso, a determinação em chinês também é indicada por outros meios gramaticais como por exemplo, posição frásica.

Os nomes em chinês mostram uma forte inclinação para serem interpretados como definidos em posições propensas para a determinação e uma forte inclinação para serem indefinidos em posições propensas para a indeterminação. Chen (2004, p. 1168) indica as posições inclinadas para a determinação na língua chinesa: sujeito, Ba (prep.) + objeto, objeto pré-verbal, e primeiro objeto do verbo bitransitivo. Então, a maior diferença entre o português e o chinês assenta no fato de que. além da autonomia morfológica e peso fonológico, os mecanismos de codificação do primeiro têm sofrido pleno processo de gramaticalização e desenvolvido usos altamente especializados para indicar a definitude de entidades. O segundo codifica principalmente, além da definitude, outros traços gramaticais, tais como deítico, topicalização, entre outros. O artigo português não tem uma entrada lexical para a definitude. É sempre expletivo (semanticamente vago) e só é selecionado se um sintagma determinante é projetado. Por esta razão, a relação entre forma-função no desenvolvimento da interlíngua no caso do artigo torna-se acidental porque os aprendizes chineses não têm formas correspondentes na sua língua materna.

O presente estudo é importante por poder contribuir para a área de estudo no que respeita à aquisição do $A D$ e, consequentemente, para o conhecimento da aquisição de PLA. A evidenciação das variações ocorridas no uso do AD por aprendizes chineses ajuda a compreender os processos mentais subjacentes à sua aquisição desta categoria gramatical.

\section{Recolha e tratamento dos dados}

O estudo foi feito junto de 51 alunos chineses do curso de licenciatura em Estudos Portugueses da Universidade de Macau que tinham mais que 700 horas de aprendizagem de português como lingua estrangeira. Um corpus de produção oral é construido com base nos dados recolhidos através da gravação e transcrição das entrevistas individuais realizadas com a duração de 30 a 40 minutos, nas quais os alunos falaram da sua vida, do seu estudo e também das suas opiniões pessoais sobre vários aspetos da sociedade em que viviam. Nos textos de transcrição, os nomes foram identificados e os usos desviados foram verificados e corrigidos com o apoio dum grupo de falantes nativos.

Antes de os dados serem codificados, foram excluidos do corpus nomes existentes em aforismo, provérbios e frases feitas porque o especificador costuma ser omisso; nomes próprios4; nomes em expressões de tempo; topônimos; nomes com quantificadores que exprimem a quantificação existencial; a palavra "casa" devido à demasiada frequência de ocorrência; nomes que aparecem em orações estruturalmente muito erradas. Assim, totalizavam-se 4288 dados válidos que foram posteriormente usados para as análises feitas com a utilização do SPSS.

\section{Primeiro grupo de análises}

A primeira análise refere-se aos contextos linguísticos em que se distribui o AD e o Al. Em primeiro lugar, temos abaixo a Tabela 1 que apresenta as diferenças da exatidão do uso do AD e do Al.

\footnotetext{
4 "Quando precede nomes próprios, o artigo definido não parece ser fundamental na operação de definitização e singularização: tal função é assegurada pelo nome próprio. Neste contexto, Longobardi, 1994, considera que se trata de um artigo expletivo" (MATEUS et al., 2003, p. 214)
} 
TABELA 1 - Exatidão do uso do AD e do Al

\begin{tabular}{cccc}
\hline Artigo & N & M & SD \\
\hline AD & 2772 & .91 & .292 \\
$\mathrm{Al}$ & 802 &. $\mathbf{8 2}$ & .388 \\
\hline
\end{tabular}

Fonte: Elaborada pela autora com dados da pesquisa

Os dados indicam que os informantes mostraram uma exatidão elevada no uso do AD (.91), continuando, porém, a manter dificuldades no uso do Al (.82), o que suporta a afirmação de Hawkins (2001) que o AD é adquirido mais cedo e com mais facilidade do que o Al. Ao mesmo tempo, também reflete a "direcionalidade", este padrão de desenvolvimento da aquisição do artigo de Mayo (2009). Lardiere explica que "o AD em inglês não precisa de levar em conta o traço Num e a distinção contável/massivo, o que o torna menos complexo do que o Al pelo menos neste aspeto" (2004, p. 335).

No entanto, a exatidão elevada no contexto do AD não significa naturalmente que os informantes têm um desempenho correto no uso do AD, uma vez que o fenômeno da generalização excessiva do AD pode causar uma "exatidão falsa". Para abordar esta questão, vemos como é o uso do $A D$ em relação ao contexto do $\mathrm{Al}$ e ao contexto em que não se pede o artigo.

TABELA 2 -Uso do AD no contexto do uso do Al e no contexto da omissão do artigo

\begin{tabular}{cccc}
\hline Contexto & N & M & SD \\
\hline $\begin{array}{c}\text { Contexto do uso do Al } \\
\begin{array}{c}\text { Contexto da omissão do } \\
\text { artigo }\end{array}\end{array}$ & 802 & $\mathbf{. 1 4}$ & .348 \\
\hline
\end{tabular}

Fonte: Elaborada pela autora com dados da pesquisa

A partir da Tabela 2, descobrimos que a generalização excessiva do AD foi encontrada nos nossos dados. O mean da generalização excessiva do AD no contexto do Al era .14, e no contexto da omissão do artigo, um pouco mais elevado .28. Segundo a ordem do desenvolvimento do artigo esboçada por Hawkins (2001), os aprendizes co- meçam com nomes nus. Depois, o AD surge no estabelecimento da categoria $\mathrm{D}$ anterior ao aparecimento do Al. Então, no processo da aquisição do artigo em português, os nossos informantes chineses estão numa fase em que a tendência é para acabar com a inundação de nomes nus e principalmente experimentar usar o $A D$, mesmo nos contextos em que não é pedido. Por consequência, apresenta-se outra propriedade da sua interlingua, a generalização excessiva do AD nos contextos em que não se deve usar.

Dado que um dos primeiros objetivos do presente estudo é testar se a transferência de língua materna está presente no uso do artigo, ou seja, a característica de linguas maternas sem o sistema de artigo se revela na interlingua dos informantes. Observamos a seguir a omissão do artigo nos contextos do uso do AD e do Al.

TABELA 3 - Omissão do artigo nos contextos do uso do $A D$ e do $A l$

\begin{tabular}{cccc}
\hline Contexto & N & M & SD \\
\hline Contexto do uso do AD & 2772 & .09 & .287 \\
Contexto do uso do Al & 802 & .04 & .204 \\
\hline
\end{tabular}

Fonte: Elaborada pela autora com dados da pesquisa

Os dados da Tabela 3 mostram a omissão do artigo nos contextos obrigatórios do AD e Al, embora menos marcada em comparação com a generalização excessiva do AD. A omissão do artigo no contexto obrigatório do AD e do Al apresenta-se em means de. 09 e de .04, respetivamente.

Encontram-se descritas, anteriormente no presente estudo, a influência da língua materna na aquisição do artigo e a evidência da omissão do artigo por aprendizes de LA que não têm o artigo na sua língua materna. Os nossos resultados não forneceram provas muito relevantes para este fenômeno. Nesta circunstância, como é que se explicam os resultados encontrados no nosso trabalho?

Uma explicação possivel é que os informantes já não estão na fase inicial da aquisição (em que os aprendizes devem transferir as caracteristicas da língua materna para $S_{0}$ da sua interlingua, aqui, 
será a omissão do artigo). Com mais exposição à língua-alvo, os informantes vão sabendo que existe uma categoria funcional D(eterminante) na lingua portuguesa que não se encontra na sua lingua materna e que é preciso estabelecer uma especificação nova para esta categoria. Então eles estão numa fase em que pretendem afastar-se da influência da lingua materna, recorrendo à categoria do artigo para expressar a determinação de nomes, não conseguindo, porém, fugir totalmente da influência da língua materna. É por esta razão que, embora não tenha sido encontrada uma influência muito notada da lingua materna, a omissão do artigo ainda existe.

A partir daqui, podemos julgar que a transferência da língua materna, uma das fontes da interlíngua dos aprendizes de LA, vai perder o seu peso à medida que os aprendizes vão estando mais expostos ao "gatilho" da LA, ou seja, a lingua materna dos aprendizes chineses vai deixando de ter o seu impacto na aquisição de PLA. Por isso, é fundamental os aprendizes saberem que a função primária do artigo como um instrumento da língua é sinalizar gramaticalmente a presença de um nome, porque, ao ter esta noção, os aprendizes chineses podem evitar a omissão, especialmente do $A D$ em contextos em que o uso do artigo é redundante.

De acordo com a discussão acima, tirámos como pontos conclusivos que o uso do AD pelos aprendizes chineses foi problemático, caracterizado pela generalização excessiva do AD com acompanhamento reduzido da omissão do artigo, como também pelo uso mais correto do AD do que o do Al. Os mesmos aprendizes possuem uma gramática que exibe propriedades sistemáticas que não apresentam semelhanças óbvias quer com a língua materna quer com a LA.

\section{Segundo grupo de análises}

A partir das conclusões do último ponto, passamos a saber que os informantes foram mais corretos no uso do AD do que Al. Aqui vamos descobrir se eles foram corretos em todos os contextos definidos?
TABELA 4 - Uso do AD em diferentes contextos definidos

\begin{tabular}{ccc}
\hline Contexto do AD & N & Percentagem \\
\hline Presença física & 23 & .8 \\
Uso anafórico & 467 & $\mathbf{1 6 . 8}$ \\
$\begin{array}{c}\text { Conhecimento } \\
\text { compartilhado }\end{array}$ & 826 & $\mathbf{2 9 . 8}$ \\
$\begin{array}{c}\text { Referência por associação } \\
\text { Informação contida na }\end{array}$ & 41 & 1.5 \\
própria expressão nominal & 1010 & $\mathbf{3 6 . 4}$ \\
Genérico & 262 & 9.5 \\
Usos fixos & 143 & 5.2 \\
Total & 2772 & 100.0 \\
\hline
\end{tabular}

Fonte: Elaborada pela autora com dados da pesquisa

$O A D$ é mais usado no contexto em que um referente é determinado pela informação contida na própria expressão nominal com a percentagem do uso de $36.4 \%$. O segundo e o terceiro usos mais frequentes ocorrem quando um referente é determinado pelo conhecimento compartilhado e pelo uso anafórico, com as percentagens de $29.8 \%$ e $16.8 \%$ respetivamente. Os nossos informantes mostraram a tendência para usar o AD na situação em que a determinação de um referente é atribuida pela informação contida na própria expressão nominal.

TABELA 5 - Exatidão do AD em diferentes contextos definidos

\begin{tabular}{cccc}
\hline Contexto do AD & N & M & SD \\
\hline Presença física & 23 & $\mathbf{1 . 0 0}$ & .000 \\
Uso anafórico & 467 & .91 & .292 \\
Conhecimento compartilhado & 826 & .88 & .322 \\
$\begin{array}{c}\text { Referência por associação } \\
\text { Informação contida na própria } \\
\text { expressão nominal }\end{array}$ & 1010 & .91 & .292 \\
Genérico & & & .156 \\
Usos fixos & 262 & .95 & .218 \\
Total & 143 & .93 & .256 \\
& 2772 & .91 & .292 \\
\hline
\end{tabular}

Fonte: Elaborada pela autora com dados da pesquisa 
Os dados mostram que o uso do AD em todos os contextos foi correto, com means de exatidão altos e que o uso situacional foi o mais correto (com o mean de exatidão 1.00). Outros casos de uso do $A D$, em que um referente é determinado por elementos contextualmente existentes por associação, ou por uso anafórico também foram mais corretos, sendo os means de exatidão .98 e .95, respetivamente. O uso do AD baseado no conhecimento compartilhado foi o menos correto, com o mean de exatidão .88.

Para se examinar a correlação entre os contextos genérico e não genéricos do $A D$ e a sua exatidão, ou seja, verificar se os diferentes contextos definidos exercem a influência na exatidão do uso do AD, foi realizado o Teste Qui-Quadrado $\left(X^{2}\right)$ de Pearson. O valor do teste mostra a significância associada, .019, o que permite concluir que existe uma associação significativa dos contextos genérico e não genéricos do uso do AD com a exatidão do seu uso, já que $\mathrm{p}<.05$.

Quanto à exatidão do uso situacional, pode-se explicar que a presença física de um referente reforça o uso do $A D$, aqui com a função deítica. Lembra-se que os demonstrativos chineses, quando a sua função deítica é atenuada, são usados como marcadores de referência definida. De fato, eles são empregues em alguns contextos em que o AD é regularmente usado como marcador de referência definida. Pode-se dizer que os demonstrativos chineses estendem o seu uso para AD, revestindo-se de algumas funções que são próprias do artigo.

Isto significa que os demonstrativos chineses funcionam, em certas situações, como AD. Por esta consideração, os informantes chineses conseguiram usar o SD de forma muito correta no seu uso situacional devido à transferência positiva da lingua materna. Daí podermos afirmar a existência da influência de língua materna dos aprendizes chineses na aquisição do artigo de PLA.

Quanto à categoria não genérica do seu uso, afirmamos que o resultado está conforme com a descoberta de Liu e Gleason (2002), isto é, o uso de presença física (situacional) é adquirido com mais facilidade e anteriormente em relação aos usos em que a referência é determinada por um elemento da estrutura discursiva (estrutural e textual). O último uso é no contexto em que a referência é determinada pelo conhecimento compartilhado entre o falante e o ouvinte (uso cultural). Os seguintes exemplos mostram a ordem da exatidão do uso do AD em diferentes contextos detetada no nosso corpus.

E9 INF: A IMAGEM 5 está muito desordem.

\section{[Uso de presença física]}

E10 INF: Porque ele, acho que O OBJECTIVO DELES não, não é bom.

\section{[Informação contida na própria ex- pressão nominal]}

E11 DOC: Não vê as notícias em português?

INF: Ah...já tentei mas não consigo.

DOC: Porquê?

INF: Ah, já, só percebi O TEMA, mas ah, tudo ah, não, ah...só percebi um pouco, sim, não é tudo. (10019)

\section{[Referência por associação]}

\section{E12 INF: Só dois. Duas cantoras.}

DOC: Mais nada?

INF: Mais nada. Não sei ah...não sei o nome dO CANTOR.

\section{[Uso anafórico]}

E13 INF: Normalmente falo com AS AMIGAS

\section{[Conhecimento compartilhado]}

Foi ainda verificado que a omissão do artigo é ligeiramente mais marcada no contexto em que a determinação de referência é evocada pelo conhecimento compartilhado do que os outros contextos. Uma consideração pragmática 
de economia no que respeita à clareza de referência pode explicar isto. Como o referente é do conhecimento do falante e do ouvinte, o uso do $A D$ já é obviamente redundante. Trenkic no seu estudo em que abordou a questão da omissão do artigo, afirmou que "a clareza de referência discursiva e a economia são as considerações principais para a decisão de falantes de segunda língua no uso ou na omissão de um artigo" (2007. p. 128). Robertson argumentou também que "quando o uso do AD é redundante, é mais provável ser omisso" (2000, p. 158). Esta explicação está em paralelo com uma propriedade da língua chinesa, língua materna dos informantes. Sendo uma língua "económica", muitas vezes quando a referencialidade de um SD não está marcada lexicalmente nem pela posição, é a propriedade pragmática que entra em jogo.

Em resumo, os informantes mostraram uma exatidão elevada no uso do AD e uma tendência para o seu uso nos contextos em que a determinação da entidade é diretamente evocada pela informação contida na própria expressão nominal ou pelo conhecimento compartilhado entre o falante e o ouvinte. Quanto à exatidão do seu uso, além do uso genérico, os usos não genéricos em que a determinação de uma entidade é evocada por presença física, por associação, por uso anafórico, ou por informação contida na própria expressão nominal, foram muito corretos.

Comparativamente, o uso do AD no contexto em que a determinação da entidade é evocada pelo conhecimento compartilhado foi ligeiramente problemático. Então, está afirmado que certos usos do AD são mais fáceis de adquirir do que outros. Este achado do presente trabalho suporta a declaração de Liu e Gleason (2002) que o uso situacional é anterior aos usos estrutural e textual, que precedem o uso cultural.

\section{Considerações finais}

Considerando que os aprendizes chineses sem o sistema de artigo na sua língua materna encaram sempre dificuldades na aquisição do artigo de PLA, o presente estudo empírico destaca a importância da pesquisa em questão, tendo revelado que os aprendizes chineses mostraram uma exatidão elevada no uso do AD, contrastando com o fenômeno de mais ocorrência do uso desviado do Al. A partir dos respetivos dados, passámos a saber que, apesar da exatidão elevada detetada no seu uso, o AD foi generalizado excessivamente. Por outro lado, foi descoberto ainda que, em paralelo com a inundação do $A D$, a omissão do artigo nos contextos obrigatórios do AD e do AI não foi muito marcada. Os aprendizes estão numa fase em que pretendem afastar-se da influência da língua materna, recorrendo à categoria do artigo para expressar a determinação de nomes, não conseguindo, porém, fugir totalmente da influência da lingua materna.

A partir daqui, podemos julgar que a transferência da língua materna, uma das fontes da interlíngua dos aprendizes de L2, vai perdendo o seu peso à medida que os aprendizes vão estando mais expostos ao "gatilho" da LA. Foi também aprovado, no presente estudo, o fenômeno de "direccionalidade" denominado por Mayo (2009), o que suporta a hipótese de a aquisição do AD ser anterior à do $\mathrm{Al}$.

Por outro lado, o uso do AD no contexto em que a determinação de um referente é evocada pela informação contida na própria expressão nominal foi o mais frequente e o uso do AD no contexto da presença física foi o mais correto. Por isso, pode-se dizer que certos usos do AD são mais fáceis de adquirir do que outros. Este resultado do presente trabalho suporta a afirmação de Liu e Gleason (2002) sobre a ordem de aquisição do AD. Nas implicações pedagógicas dos resultados, os diferentes usos do AD são aprendidos gradualmente e com dificuldade. Portanto, não deve esperar-se que os aprendizes chineses compreendam esses usos ao mesmo tempo, sendo, porém, "introduzidos gradualmente por um longo periodo e com reciclagem" (KADER, 2017, p. 45).

\section{Referências}

CHAUDRON, Craig; PARKER, Kate. Discourse markedness and structural markedness: The acquisition of English noun phrases. Studies in Second Language Acquisition, v. 12, p. 43-64, 1990. https://doi.org/10.1017/ S0272263100008731 
CHEN, Ping. Identifiability and definiteness in Chinese. Linguistic - an Interdisciplinary Journal of the Language Sciences. Haia: Mouton, 2004. Volume 42-6. https://doi. org/10.1515/ling.2004.42.6.1129

CHO, Jacee; SLABAKOVA, Roumyana. Interpreting definiteness in a second language without articles: The case of L2 Russian. Second Language Research, v. 30, n. 2, p. 159-190, 2014. https://doi. org/10.1177/0267658313509647

CUNHA, Celso; CINTRA, Lindley. Nova gramática do português contemporâneo. 17. ed. Lisboa: Edições João Sá da Costa, 2002.

HAWKINS, John A. Definiteness and indefiniteness. San Diego, CA: Academic Press, 1978

HAWKINS, Roger. Second language syntax. Oxford: Blackwell Publishing, 2001.

HUEBNER, Thorn. A Longitudinal analysis of the acquisition of English. Ann Arbor: Karoma, 1983.

HUEBNER, Thorn. System and variability in interlanguage syntax. Language Learning, v. 35, p. 141- 63 . 1985. https://doi.org/10.1111/j.1467-1770.1985.tb01022.x

IONIN, Tania, et al. Sources of linguistic knowledge in the second language acquisition of English articles. Lingua, v. 118 , n. 4, p. 554-576, 2008. https://doi.org/10.1016/j. lingua.2006.11.012

KADER, Aly. Acquisition of the nongeneric use of the definite article the by Egyptian EFL learners. تىلك :ل

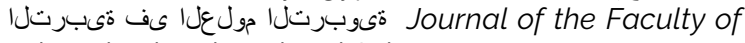
Education in Educational Sciences, v. 41, p. 15-54, 2017. https://doi.org/10.21608/jfees.2017.84148

KIM, Han Chul. Aquisição do artigo definido em português como segunda lingua por aprendizes coreanos. 2005 Tese (Doutorado em Letras) - Universidade Federal do Rio Grande do Sul, Porto Alegre, 2005

LARDIERE, Donna. Knowledge of definiteness despite variable article omission in second language acquisition, In: BRUGOS, Alejna; MICCIULLA, Linnea.; SMITH, Christine (ed.). BUCLD 28 Proceedings. Somerville, MA: Cascadilla Press, 2004. p. 328-339.

LARDIERE, Donna. Missing the trees for the forest: Morphology in second language acquisition. Second Language, v. 15, p. 5-28, 2016.

LIU, Dilin; GLEASON, Johanna L. Acquisition of the article the by nonnative speakers of English. An analysis of four nongeneric uses. Studies in Second Language Acquisition, v. 24, n. 1, p. 1-26, 2002. https://doi.org/10.1017/ $\underline{\mathrm{S} 0272263102001018}$

LU, Crystal F-C. The acquisition of English article by Chinese learners. Second Language Research, v. 20, n. 1, p. $43-78,2001$

MASTER, Peter. A Cross-linguistic interlanguage analysis of the acquisition of the English article system. Unpublished doctoral dissertation, UCLA, 1987.

MATEUS, Maria Helena Mira et al. Gramática da Lingua Portuguesa. Lisboa: Editorial Caminho, SA, 2003.
MAYO, María del Pilar García. Article choice in L2 English by Spanish speakers. In: MAYO, Maria del Pilar Garcia; HAWKINS, Roger (ed.). Second language acquisition of articles. John Benjamins Publishing Company, 2009.

MURPHY, Susan. Knowledge and production of English articles by advanced second language learners. Dissertação (Mestrado) - Universidade de Texas, Austin, 1997.

PARODI, Teresa et al. On the L2 acquisition of the morphosyntax of German nominals. Essex Research Reports in Linguistics, v. 15, p. 1-44, 1997.

ROBERTSON, Daniel. Variability in the use of the English article system by Chinese learners of English. Second Language Research, v. 16, n. 2, p. 135-172, 2000. https:// doi.org/10.1191/026765800672262975

SNAPE, Neal. Definite generic vs. definite unique in L2 acquisition. Journal of the European Second Language Association, v. 2, n. 1, p. 83-95, 2018. https://doi. org/10.22599/jesla.46

TRENKIC, Danijela. Variability in L2 article production - beyond the representational deficit vs. processing constraints debate. Second Language Research, v. 23, n. 3, p. 289-327, 2007. https://doi org/10.1177/0267658307077643

THOMAS, Margaret. The acquisition of English articles by first and second language learners. Applied Psycholinguistics, v. 10, p. 335-355, 1989. https://doi. org/10.1017/S0142716400008663

WHITE, Lydia. Second language acquisition and universal grammar. Cambridge: Cambridge University Press, 2003

YANG, Yuan; HE, Huaqing. Corpus-based study on definite article errors in English writing. International Journal of Arts and Commerce, v. 5, n. 6, p. 24-31, 2016.

YOUNG, Richard. Form-function relations in articles in English interlanguage. In: BAYLEY, Robert; PRESTON, Dennis R. (ed.). Second language acquisition and linguistic variation. John Benjamins Publishing Company, 1996.

ZHANG, Jing. Comparação do sistema de determinação/indeterminação entre a lingua portuguesa e a lingua chinesa. In: GROSSO, Maria J.; GODINHO, Ana P.C. (ed.). O português na China. Lisboa: Lidel, 2014

\section{Jing Zhang}

Doutora em Linguística, professora auxiliar do Departamento de Português da Faculdade de Letras da Universidade de Macau

Macau, China

\section{Endereço para correspondência}

Jing Zhang

Avenida da Universidade

Taipa

Macau, China 